Nicole Jasmin Bettinger

\title{
Prozessmodelle im Zivilverfahrensrecht
}

Erfolg des Hauptverhandlungsmodells auch in der Schweiz?

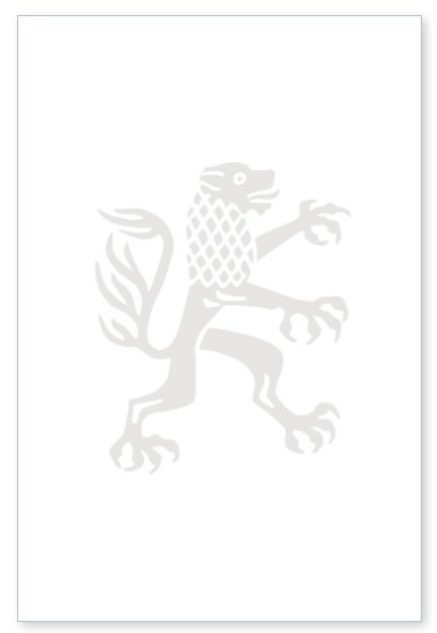

2016. XVIII, 314 Seiten. VVerfR 123

ISBN 978-3-16-154627-3

DOI 10.1628/978-3-16-154627-3

eBook PDF $89,00 €$

ISBN 978-3-16-154300-5

fadengeheftete Broschur $89,00 €$
Zur Gewährung umfassenden Rechtsschutzes bedarf es bei der Gestaltung von Verfahrensrecht eines Ausgleichs zwischen Formstrenge und Freiheit. Daneben darf allerdings auch die kulturelle Komponente des Rechts nicht vernachlässigt werden. Dieser Gedanke führte im Zivilprozessrecht zur Ausbildung dreier Prozessmodelle, die den möglichen Verfahrensablauf im Erkenntnisverfahren abbilden. Das Hauptverhandlungsmodell verdrängt derzeit bei Reformen in unterschiedlichen Rechtskulturen das trial-Modell und das italienisch-kanonische Modell immer mehr. Aufgrund der kulturellen Vielfalt der Schweiz sah sich der Schweizer Gesetzgeber einer Vielzahl kantonaler Regelungen und der Umsetzung verschiedener Prozessmodelle gegenüber, als er 2011 den Schritt hin zur ersten eidgenössischen Zivilprozessordnung wagte. Die Autorin untersucht neben dem Erfolg des Hauptverhandlungsmodells, wie der Schweizer Gesetzgeber ein konsensfähiges Regelwerk geschaffen hat und wie dieses im Kontext der aktuellen Rechtsentwicklung im Zivilprozessrecht zu sehen ist.

Nicole Jasmin Bettinger Geboren 1988; Studium der Rechtswissenschaften an der Universität Freiburg i. Br.; wissenschaftliche Hilfskraft am Institut für deutsches und ausländisches Zivilprozessrecht in Freiburg i. Br.; 2013-14 wissenschaftliche Assistentin an der chaire de droit allemand der Université de Lausanne, Schweiz; seit 2014 Rechtsreferendarin am Landgericht Freiburg i. Br.

Jetzt bestellen:

https://mohrsiebeck.com/buch/prozessmodelle-im-zivilverfahrensrecht-9783161546273?no_cache=1 order@mohrsiebeck.com

Telefon: +49 (0)7071-923-17

Telefax: +49 (0)7071-51104 